\title{
Relaciones culturales en el «Nuevo orden»: la Alemania nazi y la España de Franco*
}

\author{
Marició Janué i Miret \\ Universitat Pompeu Fabra
}

RESUMEN: El artículo analiza el papel que la cultura jugó en las relaciones entre Alemania y España en la etapa nacionalsocialista. Esta cuestión es relevante historiográficamente por dos motivos principales. En primer lugar, porque no disponemos hasta hoy día de una visión de conjunto sobre las relaciones culturales entre ambos países en dicha etapa. En segundo lugar, porque cuando los nacionalsocialistas alcanzaron el poder en el año 1933 la cultura se había convertido ya desde hacía tiempo en un elemento esencial de la política exterior de las principales potencias europeas y, con ello, también de Alemania. El artículo explica las razones de ambos Estados para intensificar las relaciones culturales mutuas. Con ello, pretende contribuir a esclarecer las afinidades entre ambos regímenes. El análisis se basa, tanto en estudios existentes ya sobre aspectos parciales de las relaciones culturales entre ambos países, como en trabajos resultado de la investigación propia. Se concluye que las tensiones entre los diferentes sectores políticos que buscaban hegemonía en el interior del régimen franquista no bastan para explicar las oscilaciones en la intensidad de las relaciones culturales. El factor decisivo fue el desarrollo negativo para Alemania de la Segunda Guerra Mundial. La investigación demuestra que no deben subestimarse, ni las coincidencias ideológicas entre ambos regímenes, ni el nivel de fascistización de la dictadura de Franco en sus primeros estadios.

\section{Palabras ClaVE: Franquismo; Nacionalsocialismo; Fascismo; Rela- ciones hispano-alemanas; Relaciones culturales; Política cultural exterior.}

* Quiero agradecer a los evaluadores de la revista su atenta lectura del artículo, sus comentarios y sus acertadas recomendaciones que han contribuido a mejorarlo. La responsabilidad sobre el contenido del artículo, sin embargo, es mía. 


\section{Cultural Relations in the "New Order»: Nazi Germany and Franco's Spain}

ABSTRACT: The article analyzes the role that culture played in German-Spanish relations during National-Socialism. This is a relevant historiographical question for two main reasons. The first, that we still lack an overall approach on the cultural relations between the two countries in that period. The second, that when the national-socialists came to power in 1933, culture had already become for a long time an essential part of foreign politics of the most important European powers, and consequently also of Germany. The article explains the motivations for intensifying cultural relations for both countries. Its ultimate objective is to get a clearer idea about the affinities between Nazi Germany and the Francoist regime. We base the analysis in our own research in archives as well as in the already existing literature on partial aspects of the cultural relations between the two countries. We conclude that the tensions between the different political sectors which looked for hegemony inside the francoist regime were not the decisive factor to explain the variations in the intensity of the cultural relations between the two countries. The decisive element was the negative evolution of the Second World War for Germany. Finally, the research proves that the ideological coincidences between the two regimes and the level of fascistization of Franco's dictatorship in its first stages should not be underestimated.

KEY WORDS: Francoist Spain; National-Socialism; Fascism; German-Spanish relations; cultural relations; Foreign cultural politics.

Los vínculos económicos, militares y diplomáticos entre la Alemania Nazi y la España de Franco han recibido ya una notable atención por parte de los historiadores ${ }^{1}$. Por el contrario, no disponemos hasta hoy de una visión de conjunto sobre las relaciones culturales entre ambos regímenes en dicha eta$\mathrm{pa}^{2}$. Esta cuestión es relevante historiográficamente, también, porque cuando los nacionalsocialistas alcanzaron el poder en el año 1933, hacía ya tiempo que la cultura se había convertido en un elemento esencial de la política exterior de las principales potencias europeas y, con ello, también de Alemania.

Este artículo se propone analizar el papel que jugó la cultura en las relaciones entre España y Alemania en la etapa nacionalsocialista. Se prestará atención, principalmente, a los siguientes cuatro aspectos. En primer lugar, al significado que el régimen nacionalsocialista otorgó a la política cultural exterior en sus relaciones con España. Nos preguntaremos, en este ámbito, en

1 BERNECKER, 2002. GARCÍA PÉREZ, 1996. LEITZ, 1996; 1999. VIÑAS, 2001. Entre otros.

2 La única hasta ahora, HERA MARTÍNEZ, 2002: 223-431, que se detiene en 1939. Dedica las primeras páginas al período a partir de 1939, SANZ DÍAZ, 2010: 361-380. 
qué medida los objetivos políticos y económicos imperialistas nazis condicionaron la extrema politización de la política cultural exterior alemana en relación con España. Vinculado a este primer aspecto lo está el segundo, a saber, las variaciones en la intensidad de las relaciones culturales entre ambos Estados a lo largo del período considerado. En relación con esta cuestión, tendremos en cuenta, tanto las continuidades a lo largo del período, como las fracturas que en las relaciones culturales mutuas provocaron hechos clave como el auge al poder de los nacionalsocialistas, el estallido de la Guerra Civil española o el establecimiento de la dictadura de Franco. Considerando la importancia que habían jugado ya los intereses económicos alemanes en España en períodos precedentes como impulsores de las relaciones culturales mutuas, el tercer aspecto que quiere reflejarse es en qué medida fue éste también el caso en la etapa nacionalsocialista. Finalmente, por lo que hace al cuarto aspecto, se trata de analizar cómo, tanto en Alemania, como en España, las variaciones en las respectivas circunstancias en el interior, así como en la coyuntura política internacional a lo largo del período, condicionaron las relaciones culturales entre ambos países y las actitudes de cada Estado frente al otro.

El objetivo último del artículo es explicar las razones de ambos Estados para intensificar las relaciones culturales mutuas en la etapa. Con ello, quiere contribuirse a esclarecer las afinidades entre la Alemania Nazi y el régimen de Franco. El análisis se lleva a cabo sobre la base de estudios parciales existentes sobre aspectos diversos de las relaciones culturales entre ambos Estados, así como sobre documentación obtenida en la investigación propia en diferentes archivos en España y Alemania y consignada, de manera detallada, en publicaciones diversas que referiremos.

\section{LA INSTITUCIONALIZACIÓN DE LAS RELACIONES CULTURALES MUTUAS EN LA ETAPA DE ENTREGUERRAS}

Después de la fundación del Imperio Alemán en 1871, España pasó a desempeñar un papel relevante en la lucha de Alemania para conquistar mercados y recursos en la periferia europea y en Ultramar. España exportó al país germano, sobre todo, alimentos y materias primas; y Alemania a España, productos elaborados, especialmente, de acero y maquinaria. Hasta la Primera Guerra Mundial, las industrias alemanas, sobre todo las electrotécnicas y químicas, penetraron en el mercado español apoyadas por los grandes bancos alemanes.

En esta etapa, la política cultural exterior se convirtió para las grandes potencias europeas, y con ello también para Alemania, en un medio esencial de la propaganda política y la expansión del poder ${ }^{3}$. De acuerdo con ello, el creci-

\footnotetext{
3 BRUCH, 1982. DELGADO LÓPEZ-ESCALONILLA, 1992: 8-18. DÜWELL, LINK, 1981.
} 
miento del poder económico de Alemania en España tuvo efectos sobre las relaciones culturales entre ambos Estados. Fue justo en estos momentos cuando se fundaron las primeras escuelas alemanas en España, la primera en Barcelona en 1894 y la segunda en Madrid dos años más tarde ${ }^{4}$. También en estos años, tuvo lugar un primer florecimiento de la romanística alemana ${ }^{5}$. Esto, a su vez, tuvo como resultado un incremento del interés de los intelectuales españoles por la cultura y la ciencia alemanas ${ }^{6}$. Con todo, hasta la Primera Guerra Mundial, las relaciones culturales hispano-alemanas se mantuvieron poco institucionalizadas. Esto se explica porque las relaciones políticas entre ambos Estados eran muy limitadas a consecuencia del reducido peso de España en el contexto internacional de la época.

Estas circunstancias cambiaron tras la derrota de Alemania en la Primera Guerra Mundial, cuando las potencias vencedoras interrumpieron las relaciones internacionales tanto económicas como científicas del país germano ${ }^{7}$. Por un lado, el Tratado de Versalles perjudicó la economía exterior alemana con la imposición de sanciones. A ello, debe añadirse que las potencias aliadas organizaron un boicot internacional a la ciencia alemana que casi duró una década. Para superar estos obstáculos al desarrollo de sus relaciones economicas y científicas con el extranjero, el país germano optó por intensificar su política cultural exterior, particularmente, con aquellos países que se habían mantenido neutrales durante la guerra. Se explica así, que fuera justamente en esta etapa cuando Alemania procediera a la institucionalización de su política cultural exterior. Se crearía entonces un departamento específico para ocuparse de ella en el seno del Ministerio de Asuntos Exteriores (Auswärtiges Amt) $(\mathrm{AA})^{8}$. En 1925, se fundó el Servicio Alemán de Intercambio Académico (Deutsche Akademische Austauschdienst) (DAAD) .

En este contexto, España, que se había mantenido neutral durante la guerra, pasó a convertirse en un país de atención preferente de la política cultural exterior alemana ${ }^{10}$. También debe considerarse el papel que España adquirió entonces para Alemania como puente hacia América Latina. Desde entonces en adelante, la institucionalización de la política cultural se convirtió en la principal estrategia de Alemania para ejercer influencia sobre España. Un

4 CHAMRAD, SANTIAGO, SCHOUWINK, 1994. ENGEL, LIEBETANZ, MOHR, PÖLLINGER, VIDOSA, 1998.

5 BRIESEMEISTER, 2010.

6 JANUÉ i MIRET, 2012a.

7 DÜWELL, 1976. MEYENN, 1988.

8 DÜWELL, 1981.

9 LAITENBERGER, 1981.

10 Han analizado las relaciones culturales en la etapa de entreguerras: HERA MARTÍNEZ, 2002. LÓPEZ SÁNCHEZ, 2003. PÖPPINGHAUS, 1999. PRESAS PUIG, 2010. REBOK, 2010; 2011. 
signo de este proceso podemos verlo en la importante expansión de la red de escuelas alemanas en España, a pesar de que su gran éxito debe vincularse, también, a las deficiencias del sistema escolar español. En la misma línea, debe situarse la creación del Centro Alemán de Estudios e Intercambio (Deutsche Wissenschaftliche Vermittlungsstelle) en Barcelona en 1923. Este centro recibió financiación oficial. Dos años más tarde, se fundó el Centro de Intercambio Intelectual Germano-Español en Madrid (Arbeitsstelle für Deutsch-Spanische Wissenschaftbeziehungen), que también fue apoyado económicamente por el AA. Estos nuevos representantes de la ciencia alemana establecieron contactos con la española Junta para Ampliación de Estudios (JAE). La JAE era entonces la institución española de apoyo a la ciencia más significactiva y representaba a los sectores más progresistas que deseaban una europeización del país. Los principales representantes de la Junta, al igual que las mentalidades progresistas de la época, interpretaban la europeización como una alternativa global al eterno subdesarrollo científico-cultural español. Esto explica su afán de conectar con la ciencia europea y de creer que la estancia sistemática de españoles en el extranjero era lo único que podía salvar al país ${ }^{11}$. Consecuentemente, la JAE organizó un sistema de becas para realizar estancias, denominadas «pensiones», con la expectativa de que quienes gracias a ellas tuvieran la oportunidad de viajar y aprender nuevos métodos y técnicas en el extranjero, a su vuelta los introducirían en los centros de enseñanza e investigación españoles. Los pensionados por la JAE se formaron en universidades de los países más destacados de Europa y en Estados Unidos. Sin embargo, demostraron una notable atracción por las instituciones académicas y científicas alemanas. Del conjunto de los investigadores que entre 1910 y 1934 recibieron becas de la JAE, casi una cuarta parte fue a Alemania ${ }^{12}$. En estos años, sólo Francia superó a Alemania como destino de los académicos españoles y a mucha distancia del tercer país, Bélgica. Así mismo, el país germano jugó un papel muy importante en la Exposición Internacional de Barcelona de 1929. Esta Exposición ofrecía una oportunidad incomparable a Alemania de mostrar, en libre competencia con sus anteriores enemigos y ante los ojos de Europa y el mundo, la recuperación de su anterior potencial industrial y científico ${ }^{13}$. Dos años más tarde, el DAAD inauguró una oficina subsidiaria en Madrid.

La institucionalización de las relaciones culturales entre ambos Estados afectó, no sólo a la expansión de la cultura alemana en España, sino también a la de la cultura española en Alemania ${ }^{14}$. Ya durante la Primera Guerra Mundial, se abrieron en Alemania los primeros institutos ibero-americanos y so-

11 GAMERO, 1988: 31; SÁNCHEZ RON, 2008: 405-462.

12 JANUÉ i MIRET, 2010.

13 JANUÉ i MIRET, 2007.

14 BRIESEMEISTER, 2000. JURETSCHKE, 2001. 
ciedades germano-españolas. El Instituto Ibero-Americano de Hamburgo (Ibero-Amerikanisches Institut Hamburg) se inauguró en 1917. A mediados de 1918, las sociedades germano-españolas se unieron en la Asociación AlemaniaEspaña (Verband Deutschland-Spanien). En 1924, se creó en Madrid una sede de la Sociedad Görres (Görresgesellschaft), un instituto científico católico alemán especializado en la investigación de la cultura española. Desde 1928, la Sociedad Görres publicó regularmente los Spanische Forschungen der Görresgesellschaft, una de las más prestigiosas revistas sobre cultura hispánica. En 1930, se fundó el Instituto Ibero-Americano de Berlín (Ibero-amerikanisches Institut) (IAI), dedicado al fomento de las relaciones culturales entre Alemania y las anteriores colonias españolas ${ }^{15}$. Al año siguiente, se inauguró, también en Berlín, la Sociedad Germano-Española (Deutsch-Spanische Gesellschaft) $(\mathrm{DSG})^{16}$. Esta sociedad se proponía profundizar las relaciones culturales y científicas entre ambos países mediante conferencias, exposiciones, debates y otros actos. Desde su fundación hasta su disolución por las fuerzas aliadas al fin de la Segunda Guerra Mundial, la DSG fue, no sólo un centro de fomento de la hispanística alemana, sino también el principal eje de las relaciones culturales bilaterales. Con ello, se convirtió también en un importante lugar de encuentro de los germanófilos españoles. Desde sus inicios, el concepto de «cultura» de los miembros de la DSG no sólo se basó en criterios de calidad científica y artística; también estuvo impregnado de sus valores conservadores y nacionalistas. Consecuentemente, tras la proclamación de la Segunda República Española en 1931, la DSG reaccionó con una actitud consciente de reserva, optando por una considerable reducción de sus actividades. Las élites de la sociedad consideraban que el carácter revolucionario que otorgaban a la República perjudicaba sus intereses políticos y económicos.

\section{LAS FISURAS ABIERTAS CON EL ASCENSO DE LOS NACIONALSOCIALISTAS AL PODER}

La llegada de los nacionalsocialistas al poder en 1933 ocasionó algunas fricciones en las relaciones culturales existentes entre Alemania y España. Dos razones principales pueden explicarlo. Por un lado, la antipatía que sentían los nacionalsocialistas por la Segunda República. Por otro lado, la poca simpatía que los círculos republicanos españoles progresistas sentían hacia los nacionalsocialistas ${ }^{17}$. Vemos un signo de ello en que en 1934 el número de

15 LIEHR, MAIHOLD, VOLLMER, 2003.

16 JANUÉ i MIRET, 2008a; 2008b.

17 BERNECKER, 2002: 158-159. HAUSMANN, 2001: 216. HERA MARTÍNEZ, 2002: 223-278. 
becas otorgadas por la JAE para realizar estancias en el país germano comenzara a decaer, a diferencia de los años anteriores en que había sido creciente ${ }^{18}$. Más tarde, un decreto franquista fechado en 1938 acabaría disolviendo la JAE. Una parte relevante de quienes en el pasado habían recibido becas de la Junta fueron objeto de purgas debido a sus posicionamientos políticos. Muchos se vieron forzados a exiliarse. Desde aquel momento, pasaría a ser el Consejo Superior de Investigaciones Científicas (CSIC) el que se haría cargo de las relaciones científicas de España con el extranjero, junto con los funcionarios del cuerpo diplomático ${ }^{19}$.

A partir del instante en que los nazis alcanzaron el poder, la política cultural exterior de Alemania se sometió, cada vez más, a los intereses de su imperialismo político y económico. Desde entonces, el trabajo científico y cultural se convirtió, más y más, en un instrumento de propaganda con el ánimo de expansión del poder. En la escuela alemana de Madrid, el proceso de identificación con el nuevo régimen se inició pronto, y esto a pesar de la ambivalente actitud del director de la institución, Willy Schulz ${ }^{20}$. Ya a finales de 1933, se celebraron allí unas jornadas escolares con participación de representantes de los demás colegios alemanes en España y Portugal cuyo objetivo era la homogeneización de su actividad docente sobre los fundamentos doctrinales del Tercer Reich. Los fondos de las bibliotecas de los colegios alemanes en España fueron depurados y en sus estantes aparecieron nuevas publicaciones que traducían el cambio político experimentado en Alemania. El DAAD, al igual que otras instituciones científicas y culturales, fue también instrumentalizado por el Tercer Reich al servicio de sus intereses en política exterior. Con esta finalidad, en los años 1933-1934 le fueron ampliadas sus atribuciones. A partir de entonces, el Centro Alemán de Estudios e Intercambio en Barcelona y el Centro de Intercambio Intelectual Germano-Español en Madrid perdieron autonomía y quedaron sometidos a las directrices del DAAD, viéndose obligados a adaptar sus actividades de acuerdo a las orientaciones políticas recibidas ${ }^{21}$.

En Alemania, también la DSG tuvo que subordinar gradualmente sus actividades a los objetivos imperialistas del nacionalsocialismo. Por un lado, se incrementó la influencia que las agencias estatales y las organizaciones del Partido Nacionalsocialista tenían en los órganos directivos de la sociedad. Por otro lado, aumentó también su capacidad económica, puesto que desde entonces pasó a recibir financiación estatal. Como resultado, la DSG pudo ampliar su capacidad de actuación. En esta etapa, la sociedad adquirió cada vez más

18 JANUÉ i MIRET, 2010.

19 DELGADO LÓPEZ-ESCALONILLA, 1992: 175. SANZ DÍAZ, 2010.

20 ENGEL; LIEBETANZ; MOHR; PÖLLINGER, VIDOSA, 1998: 88-95. HERA MARTÍNEZ, 2002: 306-312.

21 HERA MARTÍNEZ, 2002: 271-292; REBOK, 2010: 121; 2011: 174. 
relevancia, dado que pasó a actuar como mediadora entre los españoles que llegaban a Berlín y las autoridades estatales y del partido. En febrero de 1936, Wilhelm Faupel, un general retirado con un carácter autoritario, se convirtió en presidente de la Sociedad ${ }^{22}$. Faupel ya era desde 1934 presidente del Instituto Ibero-Americano de Berlín. Su objetivo máximo era convertirse en una autoridad imprescindible, no sólo para el Estado alemán y el partido Nazi, sino también para las elites económicas, culturales y políticas en España y Alemania.

\section{LA RENOVACIÓN DEL ACTIVISMO CULTURAL ALEMÁN EN ESPAÑa CON EL ESTALLIDO DE LA GUERRA CIVIL}

El estallido de la Guerra Civil en 1936 otorgó un significado especial a las relaciones germano-españolas a los ojos de las autoridades nacionalsocialistas. La lucha contra el comunismo constituía una parte fundamental de la misión que el régimen nazi pretendía cumplir en Europa y, según la explicación oficial alemana, ésta era la razón principal de la Guerra Civil española. La propaganda nacionalsocialista vinculará republicanismo y bolchevismo ${ }^{23}$. En octubre de 1936, los alemanes crearon la Legión Cóndor, una unidad militar de voluntarios con la finalidad de luchar al lado de Franco. Militares y técnicos alemanes colaboraron con el ejército de los insurgentes ${ }^{24}$. En aquel momento, el principal objetivo de la política exterior nazi era ejercer la mayor influencia posible en el diseño de la futura España «nacional». Muchos sectores de la Falange, el partido fascista español, flirtearon durante un tiempo con el nacionalsocialismo, mientras que otros sectores entre quienes daban apoyo a Franco consideraban preocupante la influencia alemana. En consecuencia, los nazis, en su intento de ejercer influencia en España, no sólo tuvieron que competir con el rival fascista italiano, sino que también tuvieron que confrontarse con la creciente desconfianza de algunos de los grupos políticos que daban apoyo a los insurgentes.

Con la finalidad de alcanzar su objetivo, el gobierno nazi buscó establecer relaciones con intelectuales y representantes de las profesiones liberales españoles favorables a la causa de Franco, dando prioridad a quienes previamente habían tenido ya contactos con la cultura alemana. Un número relevante de estas personas había recibido en el pasado becas de la JAE para realizar estancias en Alemania. Ahora, sobre la base de las nuevas ideas que habían aprendido allí, se habían convertido en ideólogos del nacionalsindicalismo

22 GLIECH, 2003.

23 BERNECKER, 2002: 161-165. HERA MARTÍNEZ, 2002: 343-357.

24 ARIAS RAMOS, 2003. 
falangista. En el mismo contexto, las universidades de Salamanca, Sevilla y Valladolid, controladas por los insurgentes, y a pesar de haber dejado de estar operantes en términos académicos por causa de la Guerra Civil, mantuvieron relaciones con universidades alemanas y hubo muchas visitas de académicos con afinidades hacia los regímenes de Hitler y Franco 25 . El DAAD y la Fundación Alexander von Humboldt (Alexander von Humboldt-Stiftung) dieron apoyo a estos intercambios y otorgaron becas ${ }^{26}$. En España, los alemanes financiaron lectorados para el estudio de la lengua alemana ${ }^{27}$. La Universidad de Salamanca fue el socio preferente para la mayoría de estas relaciones y esfuerzos durante la Guerra Civil Española. También se financiaron lectorados de lengua y literatura española en universidades alemanas. Por otro lado, el régimen nacionalsocialista prohibió en 1938 la Sociedad Görres, que consideraba hostil al gobierno del Tercer Reich ${ }^{28}$. Sus propiedades fueron incautadas y pasados tres años la sociedad fue disuelta. Sólo una vez terminada la Segunda Guerra Mundial volvería a reemerger. Desde la primavera de 1938 en adelante, la Junta de Relaciones Culturales, que fue reestablecida entonces por Franco, colaboró en la organización de los intercambios de académicos y estudiantes ${ }^{29}$.

En Alemania, Faupel, presidente de la DSG, utilizó la oportunidad que le ofrecía la Guerra Civil para convertir a la sociedad y a sí mismo en el principal contacto para los españoles que llegaban a la capital alemana, siempre que fueran considerados favorables a la causa del franquismo y el nacionalsocialismo. Hasta el reconocimiento oficial de la Junta Técnica del Estado de Franco por parte de la Alemania Nacionalsocialista a finales de 1936, las actuaciones de la DSG siguieron las líneas maestras dictadas por el Partido Nacionalsocialista. Consecuentemente, la Sociedad se concentró en dar apoyo a la representación de la Falange en Alemania ${ }^{30}$. Con posterioridad, la sociedad pasó a secundar la Falange en España. Dos hechos son relevantes para explicarlo. En primer lugar, el nombramiento de Faupel como primer embajador alemán en el gobierno de Franco en noviembre de 1936. En segundo lugar, y muy especialmente, el reforzamiento de Franco en el poder y la reorganización y subordinación bajo su mando en abril de 1937 de la Falange. Ésta pasó entonces a denominarse Falange Española Tradicionalista y de las Juntas de Ofensiva Nacionalsindicalista (FET y de las JONS). Sin embargo, Faupel no aceptó subordinar sus relaciones y las de la DSG con FET y de las JONS a las

25 BERNAL MARTÍNEZ, 2010: 215-217.

26 DELGADO LÓPEZ-ESCALONILLA, 1992: 199; HERA MARTÍNEZ, 2002: 280.

27 RODRÍGUEZ LÓPEZ, 2008.

28 REBOK, 2010: 128-131; 2011: 176.

29 DELGADO LÓPEZ-ESCALONILLA, 1992: 84-96; 1994: 268.

30 JANUÉ i MIRET, 2013. 
directrices de las autoridades del nuevo régimen de Franco. Esto culminó con su destitución como embajador.

A continuación, en febrero de 1938 Faupel regresó a la presidencia de la DSG. En este punto, se produjeron algunos cambios relevantes en la dirección de la sociedad. Uno de los más significativos fue la incorporación a la junta directiva de los directores de la Compañía Hispano-Marroquí de Transportes Ltda. (Hispano-Marokkanische Transport-Aktiengesellschaft) (HISMA), Johannes Bernhardt; y de la Sociedad de Compra de Mercancías y Materias Primas (Rohstoff- und Wareneinkaufsgesellschaft m.b.H) (ROWAK), Anton Wahle. HISMA y ROWAK constituyeron durante la Guerra Civil la base del sistema compensatorio por intercambio de mercancías del que dependían las relaciones económicas germano-españolas ${ }^{31}$. Ambas sociedades ejercerían una especie de monopolio comercial al servicio de los intereses alemanes. Además, también se sumaron a la dirección de la sociedad representantes de la Organización del NSDAP en el Extranjero (Auslandsorganisation der NSDAP) (AO) y del Ministerio de Propaganda del Reich (Reichsministerium für Volksaufklärung und Propaganda) (RVP). Después de su retorno a la dirección de la DSG y, especialmente, tras el fin de la Guerra Civil en abril de 1939, Faupel tendió a centrar las atenciones de la sociedad en falangistas prominentes con posiciones en el gobierno de Franco o que tuvieran su aprobación manifiesta.

Por otro lado, desde los inicios de 1937, las Juventudes Hitlerianas (Hitlerjungend) (HJ) y las Organizaciones Juveniles de FET y de las JONS (OJ) —que desde 1940 en adelante pasarían a denominarse Frente de Juventudes (FJ)-, intercambiaron información y revistas y también organizaron algunas actividades conjuntas $^{32}$. En octubre de 1937, diversos jefes de las HJ realizaron una estancia en Salamanca y el verano de 1938, tuvo lugar un campamento conjunto de verano en Bad Freienwalde. Aquel mismo año, el secretario nacional de las OJ formó parte de la misión española que asistió al Congreso de Nuremberg de septiembre. Estas relaciones provocaron tensiones entre las OJ de Falange y la Iglesia Católica española, que competían por la influencia en los medios juveniles.

Así mismo, hubo relaciones intensivas entre la Liga de Muchachas Alemanas (Bund Deutscher Mädel) (BDM) y la falangista Sección Femenina ${ }^{33}$. Desde 1937 hasta 1943, se han contabilizado hasta dieciséis visitas de líderes prominentes de la Sección Femenina y grupos de mujeres falangistas al país germano. Estas visitas fueron contestadas por siete visitas de representantes

31 BERNECKER, 2002: 166-169. LEITZ, 1996; 1999: 131-134. VIÑAS, 1974: 347-474; 1984; 2001: 308-521. WHEALEY, 1989: 72-94.

32 ALTED VIGIL, 1984: 234-235, 382. CAÑABATE VECINA, 2003-2004.

33 MORANT ARIÑO, 2007a; 2007b, 2013. 
del BDM a España. Estos encuentros tenían una clara significación política para ambas partes. El programa incluía viajes de estudio y giras de visita a lugares de alto simbolismo cultural. La Sección Femenina tomó al BDM como referencia. Tanto la Sección Femenina como también otros gupos juveniles españoles siguieron modelos alemanes y el Auxilio Social franquista copió algunas características de la Ayuda de Invierno (Winterhilfe) nacionalsocialista. Estas influencias, no sólo se extendieron a la estructura, sino también al contenido ideológico.

Entre las muchas actividades desarrolladas ya durante la guerra Civil para reforzar las relaciones culturales mutuas, destacan las tres exposiciones del libro alemán organizadas en diversas ciudades españolas en poder de los franquistas entre 1938 y $1941^{34}$. La primera se celebró en la primavera de 1938 en Salamanca, si bien tuvo una repercusión limitada. Entre dicembre de 1938 y julio de 1939, una exposición itinerante recorrió Sevilla, Málaga, Granada y Bilbao. Finalmente, para celebrar el fin de la Guerra Civil, se inauguró una exposición solemne en Madrid en noviembre de 1940, que tendría un epílogo altisonante en el paraninfo de la Universidad de Barcelona en febrero de 1941. La comunidad alemana en España y FET y de las JONS colaboraron en el desarrollo de estas actividades. También estas exposiciones fueron motivo de tensiones entre FET y de las JONS y otros sectores más católicos en la España franquista en un momento en que se estaban trazando los fundamentos ideológicos del nuevo régimen. Los principios ideológicos y organizativos difundidos por las publicaciones nazis que llegaron a España durante este período - como los de liderazgo, partido totalitario, aspectos de la organización del sistema educativo, el sindicalismo o el corporativismo - influyeron en aspectos prácticos del «Nuevo Orden» franquista ${ }^{35}$. Los fundamentos ideológicos del «sindicalismo vertical» franquista estuvieron influenciados, especialmente en los primeros años del régimen franquista, por el modelo de las relaciones laborales en la Alemania nazi encarnado en el Frente del Trabajo Alemán (Deutsche Arbeitsfront) (DAF). Éste era tema de muchos de los libros que los alemanes enviaron a España. Las autoridades alemanas controlaron que los libros de carácter ideológico tuvieran un peso representativo en sus envíos hacia España y que sus regalos fueran adecuadamente publicitados.

Otro ámbito cultural de apoyo nazi a la España franquista durante la Guerra Civil, fue el cinematográfico ${ }^{36}$. Por parte alemana, la fuerza impulsora vino del RVP. Durante la Guerra Civil, el RVP apoyó dos acuerdos. El primero permitía a Hispano-Film-Produktion filmar en Berlín en coproducción con

34 BERNAL MARTÍNEZ, 2007; 2010.

35 Seguimos a BERNAL MARTÍNEZ, 2010: 219-220.

36 DELGADO LÓPEZ-ESCALONILLA, 1992: 202. ESTIVILL, 1997. MESEGUER, 2004: 25-46. 
la UFA. Entre 1938 y el final de la Guerra Civil, se rodarían cinco largometrajes: Carmen la de Triana y La Canción de Aixa de Florián Rey; y El Barbero de Sevilla, Suspiros de España y Mariquilla Terremoto de Benito Perojo. El segundo acuerdo permitía a la compañía TOBIS editar y distribuir el Noticiario Español (1938). Estos acuerdos respondían, tanto a intereses económicos, como a prioridades propagandísticas del Reich. Por una parte, aspiraban a reforzar la posición de la industria cinematográfica alemana en el mercado internacional contra la competencia de Hollywood, substituyendo productos americanos por otros controlados por Berlín. Al mismo tiempo, también apuntaban al consumo local en Alemania. Las películas que venían de otros países y representaban temáticas exóticas ajenas a la realidad social y cultural de Alemania gozaban de un éxito seguro ante la audiencia, siempre que tuvieran calidad suficiente. Por otro lado, ante la opinión pública alemana era importante dejar claro cual era el bando correcto en la Guerra Civil española, a pesar del carácter ilegal de la insurgencia de Franco. Joseph Goebbels, ministro nazi de propaganda, quien en el Congreso del NSDAP de 1937 en Nüremberg pronunció un discurso sobre «La Verdad sobre España ${ }^{37}$, puede muy bien haber considerado la colaboración con los franquistas como una vía para acercar la Guerra Civil al público alemán desde un punto de vista adecuado y disfrazado como película de ficción. Además, los alemanes realizaron diversas producciones relativas a su intervención militar en la contienda española como, entre otras, Kameraden auf See (1938) de Heinz Paul sobre un barco alemán de pasajeros asaltados en aguas españolas por siniestros comunistas, aunque finalmente liberado por la marina de guerra germana; o Legión Cóndor (1939) de Karl Ritter, sobre la disciplinada eficacia y perfección tecnológica de los militares voluntarios alemanes en España.

Por su parte, los españoles miraban a la industria cinematográfica alemana buscando una posibilidad de producir películas de propaganda para la «causa nacional» y películas de ficción para su zona. Entre los documentales, el más importante sobre la Guerra Civil fue España Heróica (Helden in Spanien), montado por Joaquín Reig y producido por Hispano-Film-Produktion y FET $\mathrm{y}$ de las JONS en 1938. El documental mostraba un punto de vista fundamentalmente nazi y, consecuentemente, daba apoyo a FET y de las JONS dentro de la España de Franco.

En relación a la coproducción de películas, el proyecto fue desde el principio objeto de conflictos entre los intereses económicos de los directivos de la UFA, que temían que el producto fracasara en la taquilla, y los líderes del RVP. Como compensación por la ayuda ofrecida por la UFA, el RVP vendió una gran cantidad de películas alemanas a la España de Franco. Ilustra la

37 GOEBBELS, 1937. 
efectividad de esta forma de «política cultural» alemana la proyección en la península de películas de contenido nacionalsocialista. Un ejemplo es El Flecha Quex (Hitlerjunge Quex) (1933), la película más famosa sobre las Juventudes Hitlerianas que fue mostrada en Valladolid a inicios de 1937. Después del fin de la Guerra Civil, se firmó un nuevo acuerdo cinematográfico en Berlín en abril de 1940 que autorizaba la importación de muchas películas de ficción y documentales alemanes a España ${ }^{38}$.

Un importante paso adelante en las relaciones culturales entre ambos Estados fue el Convenio sobre la Colaboración Espiritual y Cultural entre España y Alemania firmado en Burgos en enero de 193939. Este Convenio fue precedido de acuerdos similares con Hungría, en 1936, y con Grecia, Italia y Japón, en 1938. Durante la Segunda Guerra Mundial, le siguieron otros con Bulgaria (1940), Rumanía (1941) y Eslovaquia (1942). El Convenio consideraba un amplio abanico de medidas en los ámbitos educativo e institucional y daba apoyo a la difusión de libros y traducciones. Sin embargo, no llegó nunca a ser ratificado debido a la firme oposición del Vaticano y la jerarquía de la Iglésia Católica en España, que veían con mucha prevención las infiltraciones nazis y los gravísimos peligros que encerraba su penetración ideológica para la fe de los españoles ${ }^{40}$. Esto prueba las dificultades de la dictadura franquista para mantener un equilibrio entre los diferentes sectores que habían contribuido a su victoria ${ }^{41}$. En el nivel de la política internacional, la colaboración entre el régimen nazi y el franquista alcanzó su punto álgido con la firma por parte española, en marzo de 1939, es decir, poco antes del fin de la Guerra Civil, del Pacto Antikomintern para aislar a la Unión Soviética.

\section{LA MUY RELEVANTE COLABORACIÓN CULTURAL MUTUA DURANTE LA SE- GUNDA GUERRA MUNDIAL}

Finalizada la Guerra Civil, el régimen nacionalsocialista se encontraba en una posición favorable para ejercer influencia sobre la política, la cultura y la ciencia españolas. La contribución alemana a la victoria de Franco había dejado como herencia una elevada deuda cuya liquidación Alemania podía reclamar en cualquier relación bilateral. Además, los alemanes podían contar con el apoyo de las elites académicas germanófilas. Éstas eran especialmente influyentes en las disciplinas del derecho, las ciencias sociales, la filosofía y

38 ESTIVILL, 1997.

39 DELGADO LÓPEZ-ESCALONILLA, 1994: 270; HAUSMANN, 2001: 218-219; HERA MARTÍNEZ, 2002: 404-431; SESMA LANDRÍN, 2011: 251

40 MARQUINA, 1979.

41 SESMA LANDRÍN, 2004:158. 
la ingeniería, que tenían una relevante significación ideológica. La influencia nazi también era facilitada por el contexto de aislamiento intelectual, autarquía y pronunciada orientación fascista que dominó durante los primeros años del franquismo ${ }^{42}$. En este período, la dictadura franquista miró hacia el país germano e Italia en su búsqueda de referentes culturales y para la creación de redes en los ámbitos científico y tecnológico.

En la España «nacional», las escuelas alemanas se mantuvieron. Tras la rápida reapertura decretada por el AA poco después del fin de la Guerra Civil, el número de sus alumnos incluso aumentaría ${ }^{43}$. El Tercer Reich invertiría en los años siguientes y hasta el fin de la Segunda Guerra Mundial grandes sumas de dinero en la construcción o reforma de edificios escolares en España. Hacia el final de la guerra, sólo en Chile, Suecia, Suiza y España se mantenían escuelas alemanas en funcionamiento.

Tras el estallido de la Segunda Guerra Mundial, España fue incorporada al plan nacionalsocialista de redefinición del espacio económico europeo. La industria de guerra alemana se convirtió en dependiente de los suministros españoles ${ }^{44}$. El interés alemán en vincular España al Eje se incrementó. Además, España mantenía su significado como puente hacia América Latina, donde la propaganda alemana perseguía el objetivo de contrarrestar la posición dominante de los Estados Unidos ${ }^{45}$. Este objetivo estaba de acuerdo con la intención franquista de reforzar la imagen de España en América Latina mediante la doctrina de la unidad espiritual de la «Hispanidad», la comunidad de los pueblos hispánicos ${ }^{46}$. Era precisamente alrededor de esta idea de la Hispanidad que los españoles articulaban sus pretensiones de convertirse en un «imperio cultural», si bien en sus relaciones culturales con Alemania España jugó más bien un papel receptivo ${ }^{47}$.

En este contexto, también diversos hispanistas alemanes participaron en la difusión de la nueva misión europea del imperio español. Después del fin de la Guerra Civil española, el reconocido hispanista profesor de la Universidad de Hamburgo y así mismo vinculado al Instituto Ibero-Americano de dicha ciudad, Rudolf Grossmann, comentará la nueva misión europea de la España franquista en un artículo titulado «España será de nuevo una gran potencia» ${ }^{48}$.

42 DELGADO LÓPEZ-ESCALONILLA, 1994: 269; SANZ DÍAZ, 2010. SESMA LANDRÍN, 2011: 252.

43 CHAMRAD; DONALD; SCHOUWINK, 1994: 89-116. ENGEL; LIEBETANZ; MOHR; PÖLLINGER, VIDOSA, 1998. JOHS, 1956. WAIBEL: 291-415.

44 THOMÀS, 2010.

45 HAUSMANN, 2001: 215-217. SESMA LANDRÍN, 2011: 245.

46 BERTELT, 2003. DELGADO LÓPEZ-ESCALONILLA, 1988; 1992: 121-131; 1994: 268. SAZ CAMPOS, 2003: 267-308. SESMA LANDRÍN, 2011: 245.

47 DELGADO LÓPEZ-ESCALONILLA, 1992: 203.

48 GROSSMANN, 1941. Citado por BRIESEMEISTER, 2000: 277. 
Por su parte, el Instituto Ibero-Americano de Berlín (IAI) celebrará anualmente desde su fundación la Fiesta de la Raza de la Hispanidad el 12 de octubre, donde también participará la DSG. Sin embargo, en 1942 el AA abolirá la fiesta tras la entrada de los Estados Unidos en la guerra contra Alemania y el subsiguiente rompimiento por parte de los países de América Latina de sus relaciones diplomáticas con el Reich ${ }^{49}$.

Para las autoridades españolas, el anticomunismo constituía una prioridad ideológica. En consecuencia, éstas rechazaron el Pacto Germano-Soviético, que estuvo vigente desde el verano de 1939 al de 1941. Pero, a pesar de este desacuerdo, tanto las relaciones políticas como las culturales entre ambos Estados continuaron siendo intensivas. Desde junio de 1940, España mantuvo oficialmente una política de «no beligerancia», lo que significaba que no intervendría militarmente a pesar de apoyar a las fuerzas del Eje. En septiembre de 1940, el entonces ministro español de interior, Ramón Serrano Suñer, viajó a Berlín. Un mes más tarde, el líder de las SS nazis Heinrich Himmler hizo una gira por España. Estas visitas subrayaban la gratitud española frente a quien había sido su aliado durante la Guerra Civil y ponían de relieve el deseo español de integrarse en el proyecto del Nuevo Orden nacionalsocialista 50 . También en octubre de 1940, se produjo el encuentro entre Franco y Hitler en Hendaya. En el curso de estas visitas, España fue invitada a integrarse al recién firmado Pacto Tripartito de alianza militar con Italia y Japón, aunque no llegaría a subscribirlo.

Sin embargo, en mayo de 1941 Franco llevó a cabo una reorganización de su gobierno. Como resultado, los círculos fascistas de la Falange perdieron poder a favor de los núcleos más católicos y de los sectores del ejército que no querían que España participara en el conflicto bélico. Pero, precisamente en este contexto, la Falange, consciente de que sólo una victoria del Eje podía favorecer su situación dentro del país, se decidió a profundizar sus relaciones con Berlín ${ }^{51}$.

En septiembre de 1939, se fundó el falangista Instituto de Estudios Políti$\cos (\text { IEP })^{52}$. Con la creación de este instituto, se perseguían tres objetivos ${ }^{53}$. En primer lugar, debía contribuir a incrementar la influencia falangista en la articulación jurídica del régimen de Franco. En segundo lugar, los falangistas querían superar sus déficits doctrinales. En tercer lugar, se trataba de reclutar personas de confianza con valor intelectual para la administración pública.

49 BERTELT, 2003: 68.

50 SESMA LANDRÍN, 2011: 257 ss.

51 BERNECKER, 2002: 177. DELGADO LÓPEZ-ESCALONILLA, 1992: 161 ss. JANUÉ i MIRET, 2013. SAZ CAMPOS, 2003: 342-343.

52 DELGADO LÓPEZ-ESCALONILLA, 1992: 168-171; SESMA LANDRÍN, 2004; 2011.

53 SESMA LANDRÍN, 2011: 253. 
Los miembros del IEP contactaron rápidamente con los círculos nazis para establecer intercambio cultural y científico. Las continuidades personales ayudaron en ello. Los diplomáticos del Eje vieron la creación del IEP como la abertura de una puerta importante para la penetración ideológica. Consideraban a los miembros del IEP como una élite intelectual que defendía ideas falangistas y, como tal, posicionada en principio favorablemente a la entrada de España en la guerra. El IEP sería visto por los nacionalsocialistas como el mejor representante intelectual del régimen franquista. Poco después de la fundación del IEP, la DSG recibió a sus principales representantes en la capital del Reich. Éstos siguieron visitando a menudo la DSG y algunas de las conferencias que pronunciaron en la sociedad fueron más tarde publicadas en la revista Ensayos y Estudios, editada por el Instituto Ibero-Americano de Berlín (IAI).

El IEP y su revista oficial, la Revista de Estudios Políticos (REP), importaron ideología y legislación fascista y nacionalsocialista ${ }^{54}$. El primer número de la REP contenía un artículo del jurista de orígen católico simpatizante con el nacionalsocialismo Carl Schmitt ${ }^{55}$. La teoría schmittinana del poder sería profusamente utilizada para defender al régimen de Franco, otorgándole fundamento teórico ${ }^{56}$. En 1943, Schmitt fue invitado por el IEP a dar una conferencia en la Facultad de Derecho de la Universidad de Madrid ${ }^{57}$. Las relaciones de Schmitt con los intelectuales agrupados en torno al IEP continuarían siendo estrechas durante las dos siguientes décadas. El IEP invitó también a economistas alemanes. El instituto utilizó todas las publicaciones jurídicas nacionalsocialistas que recibía para elaborar su Boletín de Legislación Extranjera. También cerró acuerdos con el Instituto Alemán de Estudios Extranjeros (Deutsches Auslandswissenschaftliches Institut), que dependía del RVP y el Instituto de Economía Mundial (Institut für Weltwirtschaft) de la Universidad de Kiel ${ }^{58}$.

En España, a principios de 1941 Serrano Suñer organizó la Asociación Hispano-Germana (AHG) ${ }^{59}$. Esta sociedad recibió apoyo del RVP y el AA nazis. La sociedad estaba encabezada por el general Moscardó, considerado un «héroe de la Guerra Civil española». Bajo la apariencia de la promoción de las relaciones culturales mutuas, la AHG funcionaba como canal de contacto entre el cuerpo diplomático alemán y las autoridades del régimen franquista. Muchos de sus miembros eran miembros también del Instituto de Es-

54 SESMA LANDRÍN, 2004; 2009; 2011.

55 SCHMITT, 1941. Reproducido en SESMA LANDRÍN, 2009: 143-182.

56 LÓPEZ GARCÍA, 1996. SÁNCHEZ-BLANCO, 2000: 105-109.

57 RODRÍGUEZ LÓPEZ, 2008: 114-115. SESMA LANDRÍN, 2011: 264-265.

58 SESMA LANDRÍN, 2011: 269.

59 JANUÉ I MIRET, 2008a; 2008b. 
tudios Políticos. La AHG apoyaba a las fuerzas del Eje. En 1942, algunos autores que habitualmente publicaban en la Revista de Estudios Políticos, editaron también el Boletín de la Asociación Hispano-Germana. En el contexto de intensivos enfrentamientos con sectores del nacionalcatolicismo, el Boletín quería ser un intento de imponer una visión falangista favorable al «Nuevo Orden» continental.

Por el lado del gobierno nazi, en la primavera de 1941 se fundó bajo su iniciativa en Madrid el Instituto de Cultura Alemán (Deutsches Wissenschaftliches Institut) (DWI). Su primer presidente fue Theodor Heinermann, filólogo romanista profesor en la Universidad de Münster. Junto a su filial en Barcelona, fundada a finales de 1942, el DWI se convirtió en el núcleo de la expansión de la cultura nazi en España ${ }^{60}$. El DWI proporcionaba cooperación científica, intercambio académico, enseñanza de lengua alemana, la creación de una biblioteca, la concesión de becas, ayuda bibliográfica, la organización de conferencias y congresos, y supervisó una red de lectorados. También tomó a su cargo la publicación de Investigación y Progreso, una revista que con anterioridad había sido publicada por el Centro de Intercambio Intelectual Germano-Español en Madrid. Además, el DWI publicó, desde 1942, el Boletín Bibliográfico, cuya edición había quedado también interrumpida durante la Guera Civil. Uno de los directores del Boletín era Hans Juretschke. Juretschke era miembro de la AHG, había impartido clases en la Universidad de Madrid, entre 1939 y 1941 como lector y, con posterioridad, como catedrático de lengua y literatura alemanas. Su tesis doctoral fue publicada en español en 1940 bajo el título España ante Francia. Al año siguiente, Juretschke recibió el nombramiento de colaborador científico auxiliar de la embajada del Tercer Reich en Madrid ${ }^{61}$.

Durante la Segunda Guerra Mundial, la Universidad de Madrid mantuvo un considerable intercambio cultural y científico con el país germano, a menudo gracias al apoyo financiero alemán ${ }^{62}$. A la vez, hubo en el conjunto de las universidades alemanas entre 1939 y 1949 hasta nueve lectorados de lengua española. El DWI mantuvo una estrecha colaboración con el español CSIC, con el DAAD, con el Instituto Ibero-Americano de Berlín y con académicos alemanes interesados en la hispanística. Durante la guerra, Alemania fue el país de destino de la mayoría de las becas otorgadas por el CSIC. Numerosos académicos alemanes participaron en actividades organizadas por centros de esta institución científica española. Ya poco después del fin de la Guerra Civil, el DAAD, siguiendo las directrices recibidas de la embajada alemana, había puesto a disposición del Ministerio de Educación español la

60 HAUSMANN, 2001.

61 JORBA, 2007. VEGA CERNUDA, 2003.

62 RODRÍGUEZ LÓPEZ, 2008. 
otorgación de becas de intercambio ${ }^{63}$. En noviembre de 1943, se fundó en el marco del DWI el Instituto Arqueológico Alemán (Deutsches Archäologisches Institut $)^{64}$. Ambos institutos fueron cerrados al fin de la Segunda Guerra Mundial y no volverían a ser abiertos hasta mediados de los años cincuenta.

Con la invasión alemana a la Unión Soviética en el verano de 1941, la ideología del Pacto Antikommintern retornó y pudo volver a ponerse en el centro de las afinidades entre los dos países ${ }^{65}$. España aceptó una mayor implicación en la guerra a través del envío de la División Azul al frente del este ${ }^{66}$. Su comandante era el general Muñoz Grandes, quien era, a la vez, un miembro prominente de la AHG. Además, España firmó el Acuerdo HispanoAlemán para el Empleo de Trabajadores Españoles en Alemania. Siguiendo este acuerdo, 10.000 trabajadores «voluntarios» españoles fueron a Alemania $^{67}$. La DSG adquirió un papel prominente en la tutela de estos trabajadores una vez llegados al país germano ${ }^{68}$. La DSG ayudó en la organización del tiempo libre de estos trabajadores mediante la enseñanza de la lengua alemana, la organización de actos musicales y teatrales, la realización de excursiones, el pase de películas españolas y la facilitación de libros y otras publicaciones con contenido ideológico acorde. Un ejemplo de éstas últimas lo encontramos en la revista Enlace, editada en Berlín desde el verano de 1942, primero por la española Delegación Especial para la Asistencia y Tutela de Obreros Españoles en Alemania y después por el Instituto Ibero-Americano de Berlín ${ }^{69}$. En esta etapa, la DSG estableció relaciones con la española AHG. Otra actividad emprendida por la DSG fue el establecimiento de delegaciones en diferentes ciudades alemanas, como Munich, Leipzig y Francfort del Meno con el objetivo de promover los estudios de hispanística.

Los años 1941-1942 estuvieron también caracterizados por contactos intensivos entre la Sección Femenina (SF) y el $\mathrm{BDM}^{70}$. La líder de la SF, Pilar Primo de Rivera, hija del dictador Miguel Primo de Rivera y hermana del fundador de la Falange José Antonio Primo de Rivera, visitaría hasta seis veces Alemania entre 1938 y 1943. Las publicaciones del BDM informarían sobre su entusiasmo por el país germano. En otoño de 1942, el Frente de Juventudes y la Sección Femenina participaron en Viena en el establecimiento

63 RODRÍGUEZ LÓPEZ, 2008: 116.

64 MAIER, SCHATTNER, 2010.

65 BERNECKER, 2002: 177. BOWEN, 2000: 40. DELGADO LÓPEZ-ESCALONILLA, 1992: 166 ss. JANUÉ I MIRET, 2008a; 2008b; 2013. SAZ CAMPOS, 2003: 369.

66 MORENO JULIÀ, 2005.

67 RODRÍGUEZ JIMÉNEZ, 2002.

68 JANUÉ I MIRET, 2012b, 2014.

69 NÚÑEZ SEIXAS, 2005.

70 MORANT ARIÑO, 2007a, 2007b. 
de la Corporación de Juventudes Europeas (Europäischer Jugendverband) ${ }^{71}$. Entre los catorce países participantes, Bulgaria, Dinamarca, Alemania, Finlandia, Flandes, Italia, Croacia, Países Bajos, Noruega, Rumanía, Eslovaquia, Hungría y Valonia, además de España, sólo esta última no era, ni miembro del Eje, ni país ocupado.

Ello no obstante, el cada vez más negativo desarrollo de la guerra para los germanos llevó consigo un gradual enfriamiento de las relaciones entre la Alemania Nazi y la España de Franco. Desde el otoño de 1942, España abandonó progresivamente su posición de «no-beligerancia» en favor de la «neutralidad $\gg^{72}$. Durante la más arriba mencionada visita de Carl Schmitt a la Universidad de Madrid en junio de 1943, fue notoria la ausencia de autoridades franquistas en el auditorio, aún más considerando que asistían habitualmente incluso a actos de menor relevancia ${ }^{73}$. La última visita de una delegación de la Sección Femenina a Alemania, encabezada por Pilar Primo de Rivera, tuvo lugar a finales de julio, el día siguiente a la deposición de Mussolini ${ }^{74}$. También este mismo año, el Ministerio de Educación español decidió cancelar las becas para estudiantes que querían visitar el país germano - de la misma manera que las de quienes tenían Italia como destino-. Desde finales de 1943, el distanciamiento de las autoridades españolas frente a las fuerzas del Eje se intensificó. A partir del verano de 1944, la interrupción de los contactos culturales con Alemania fue casi completa ${ }^{75}$.

Con todo, es también cierto que aún en marzo de 1944 la Universidad de Madrid nombró doctor honoris causa al profesor de la universidad de Munich, de ideas católico conservadoras, Karl Vossler, especialista en la cultura española. En su ensayo Die Bedeutung der spanischen Kultur für Europa (1929), Vossler había defendido ya el papel de España como maestra moral de Euro$\mathrm{pa}^{76}$. Sin embargo, en 1937 había sido forzado a retirarse prematuramente debido a su oposición al antisemitismo y al fascismo. A pesar de ello, durante la Segunda Guerra Mundial el régimen nazi lo había mandado al extranjero como embajador de la ciencia alemana. Hitler le dió permiso para aceptar la condecoración española ${ }^{77}$. En agosto de 1944, fue nombrado presidente del DWI en Madrid, aunque no llegaría a tomar posesión ${ }^{78}$.

En el mismo año 1944, el filólogo e historiador Ramón Menéndez Pidal, profesor de la Universidad de Madrid, fue nombrado doctor honoris causa por

71 MORANT ARIÑO, 2012.

72 DELGADO LÓPEZ-ESCALONILLA, 1992: 319-392., esp. 322-323.

73 SESMA LANDRÍN, 2011: 264

74 MORANT ARIÑO, 2012: 8.

75 DELGADO LÓPEZ-ESCALONILLA, 1992: 386. SANZ DÍAZ, 2010: 365-367.

76 BRIESEMEISTER, 2000: 274-279; 2010: 81.

77 HUTTON, 1999: 67-69.

78 HAUSMANN, 2001: 211-215. 
la Universidad de Bonn. Si bien Menéndez Pidal durante la Guerra Civil española se había exiliado, en 1939 había retornado a la España de Franco, donde fue acogido por los intelectuales falangistas que compartían su concepción esencialista y castellanista de España y con quienes colaboró a menudo ${ }^{79}$.

Una vez terminada la Segunda Guerra Mundial, con la definitiva derrota de Alemania, la política exterior española se reorientó hacia la mejora de las relaciones con occidente con la finalidad de debilitar la campaña internacional contra el régimen de Franco ${ }^{80}$. Cuando, a principios de la década de los cincuenta, los intercambios universitarios se renovaron, pasaron a ser la Gran Bretaña y, muy especialmente, los Estados Unidos los países que recibirían la mayoría de las visitas de los estudiantes a quienes se otorgarían becas españolas. Pero, a pesar de todo, en perspectiva, el distanciamiento entre Alemania y España, también en el ámbito cultural y científico, sólo sería parcial y temporal.

\section{CONCLUSIONES}

Después del fin de la Primera Guerra Mundial, las difíciles circunstancias en las que se encontró Alemania a consecuencia de su derrota transformaron a España, gracias a su neutralidad, en un objetivo prioritario de la política cultural exterior alemana. Los nacionalsocialistas reconocieron la relevancia de la política cultural exterior en sus relaciones con España, si bien su concepto de cultura se caracterizó por una radical parcialidad ideológica acorde con sus objetivos políticos y económicos imperialistas. Durante la etapa nacionalsocialista, las fronteras entre cultura y propaganda eran muy difusas. En este período, los intereses económicos alemanes en España desempeñaron un papel importante en la promoción de las relaciones culturales entre ambos países, como también lo habían jugado en las etapas precedentes. La llegada al poder de los nacionalsocialistas ocasionó inicialmente algunas fricciones en las relaciones culturales existentes entre el país germano y España. Esto se explica, por un lado, por la antipatía de los nacionalsocialistas hacia la Segunda República Española; por otro, por el distanciamiento de los sectores progresistas del régimen republicano español de la Alemania nazi. Como consecuencia, algunos de los contactos culturales se interrumpieron. Las instituciones alemanas que hasta entonces habían apoyado el intercambio cultural y científico fueron ahora, cuando no disueltas, sometidas a los intereses nacionalsocialistas. A pesar de ello, algunas continuidades personales en las relaciones culturales entre ambos países permitieron que después del estallido de la Guerra Civil española los contactos se intensificaran de nuevo.

79 SAZ CAMPOS, 2003. SESMA LANDRÍN, 2009: 297.

80 BERNECKER, 2002: 179-181. SANZ DÍAZ, 2008; 2010. 
La Guerra Civil incrementó la relevancia de las relaciones culturales germano-españolas a los ojos de las autoridades nacionalsocialistas. Éstas procuraron ejercer la mayor influencia posible en la construcción de la España «nacional». Con esta finalidad, el gobierno nacionalsocialista apoyó el establecimiento de relaciones con intelectuales españoles y representantes de las profesiones liberales que diesen apoyo a Franco. En este contexto, se dio prioridad a quienes en el pasado ya habían tenido contactos con la cultura alemana.

La administración nacionalsocialista de la política cultural exterior reprodujo la forma de proceder general de su sistema político. Una manifestación de ello la vemos en la profusión de instituciones oficiales o semioficiales que trabajaban en los mismos ámbitos sin una definición normativa clara de sus funciones ${ }^{81}$. Como resultado, se produjo un estado de competencia permanente entre estas instituciones. Esta política permitió a sus diferentes líderes establecer pequeñas plataformas de poder que buscaban permanentemente expandirse. No obstante, los elementos de ineficiencia e irracionalidad administrativa que acabamos de describir, se combinaron con la introducción de una metodología y técnica modernas. Como consecuencia, se lograron resultados relevantes en la aspiración de conseguir la hegemonía ideológica. Con todo, los nazis tuvieron que confrontarse en este objetivo, no sólo con el rival fascista italiano, sino también con los diferentes grupos políticos que daban apoyo a Franco. Los receptores de la política cultural nacionalsocialista fueron, principalmente, los sectores más radicalizados de la Falange, partido que competía con las otras fuerzas franquistas, especialmente los nacionalcatólicos. Durante la Guerra Civil y los primeros años de la dictadura de Franco, los intelectuales de la Falange desempeñaron un papel relevante en el corazón de las elites franquistas.

Con el estallido de la Segunda Guerra Mundial, las relaciones culturales entre los dos países se intensificaron aún más. La guerra incrementó, tanto el valor económico de España para Alemania, en tanto que proveedora de materias primas para su industria de guerra; como también su significado en tanto que puente hacia América Latina. El interés alemán por reforzar los vínculos de España con América Latina coincidía con los intereses imperialistas franquistas. Con todo, en las relaciones culturales con Alemania, España jugó un papel más bien receptivo. El mayor atraso socioeconómico español condicionó la hegemonía del régimen nacionalsocialista en el ámbito de la política cultural. Con posterioridad a la reorganización del gobierno de Franco en mayo de 1941, los sectores de la Falange favorables a la causa del Eje perdieron cada vez más poder. Sin embargo, esto no hizo disminuir la intensidad de las relaciones culturales. Precisamente en este contexto, la Falange, consciente de

81 SESMA LANDRÍN, 2011: 50. 
que sólo una victoria del Eje podía mejorar su situación dentro de España, decidió intensificar sus relaciones con Berlín.

En realidad, las tensiones en el interior del régimen franquista entre los diferentes sectores políticos que buscaban hegemonía no bastan para explicar las oscilaciones en la intensidad de las relaciones culturales entre ambos países. El factor decisivo fue mucho más el desarrollo de la Segunda Guerra Mundial ${ }^{82}$. Sólo cuando hubo algunas evidencias de que Alemania podía perder la guerra, empezó el régimen franquista a reducir de manera decidida las relaciones culturales mutuas. Hasta ese momento, los falangistas e incluso el mismo Franco se consideraron a si mismos como miembros del «Nuevo orden ${ }^{83}$. Durante el período analizado, los particulares intereses nacionales de cada una de las dos dictaduras hicieron a menudo difícil llegar a acuerdos particulares en los ámbitos de la política y la economía. Ello no obstante, no deben subestimarse, ni las coincidencias ideológicas entre ambos regímenes, ni el nivel de fascistización de la dictadura de Franco en sus primeros estadios. Con todo, también es cierto que, al final, ninguno de los principales promotores de las relaciones culturales mutuas obtuvo el resultado anhelado. Ni los sectores radicales de la Falange consiguieron que España optara por la beligerancia, ni el régimen nazi pudo añadir un nuevo aliado a su esfuerzo de guerra ${ }^{84}$.

\section{BIBLIOGRAFÍA}

Alted Vigil, Alicia, Política del nuevo estado: Sobre el patrimonio cultural y la educación durante la Guerra Civil española, Madrid, Ministerio de Cultura, 1984.

Arias Ramos, Raúl, La Legión Cóndor en la Guerra Civil. El apoyo militar alemán a Franco, Madrid, La Esfera de los Libros, 2003.

Bernal Martínez, Isabel, «Libros, bibliotecas y propaganda nazi en el primer franquismo: las exposiciones del libro alemán», Hispania Nova [en línea], 7, (2007). Disponible en: http://hispanianova.rediris.es/7/articulos/7a010.pdf [consultado el 7 de mayo de 2013]

Bernal Martínez, Isabel, «La Buchpropaganda nazi en el primer franquismo a través de la política de donaciones bibliográficas (1938-1939)», Ayer, 78 (Madrid, 2010), 195-232.

Bernecker, Walter L., «Alemania y España en la época del nacionalsocialismo», en Vega Cernuda, Miguel Ángel, Wegener, Henning (coords.), España y Alemania. Percepciones mutuas de cinco siglos de historia, Madrid, Editorial Complutense, 2002; 155-181.

82 BERNECKER, 2002: 179. DELGADO LÓPEZ-ESCALONILLA, 1992: 167. SESMA LANDRÍN, 2011: 279.

83 SAZ CAMPOS, 2003, pp. 341-346.

84 SESMA LANDRÍN, 2011: 247. 
Bertelt, Dawid Danilo, Rassismus als politische Inszenierung. Das Ibero-Amerikanische Institut und der Día de la Raza, en Liehr, Reinhard, Maihold, Günther, Vollmer, Günter (coords.), Ein Institut und sein General, Wilhelm von Faupel und das IberoAmerikanische Institut in der Zeit des Nationalsozialismus, Frankfurt am Main, Vervuert, 2003; 67-129

Bowen Wayne H., Spaniards and Nazi Germany. Collaboration in the new order, Columbia and London, University of Missouri Press, 2000.

Briesemeister, Dietrich, «El auge del hispanismo alemán (1918-1933)», en Salas, Jaime de, Briesemeister, Dietrich. (coords.), Las influencias de las culturas académicas alemana y española desde 1898 hasta 1936, Frankfurt a.M., Vervuert, 2000; 267-286.

Briesemeister Dietrich, «España en Alemania: sobre el desarrollo de la investigación en los siglos XIX y XX/Spanien in Deutschland: Zur entwicklung der Forschungen im 19. und 20. Jahrhundert», en Rebok, Sandra (coord.), Traspasar Fronteras. Un siglo de intercambio científico/Über Grenzen Hinaus. Ein Jahrhundert DeutschSpanische Wissenschaftsbeziehungen, Madrid, CSIC/DAAD, 2010; 57-85.

Bruch, Rüdiger vom, Weltpolitik als Kulturmission. Auswärtige Kulturpolitik und Bildungsbürgertum in Deutschland am Vorabend des Ersten Weltkrieges, Paderborn u.a., Ferdinand Schöningh, 1982.

Cañabate Vecina, José A, «La pugna entre la Iglesia Católica y el Frente de Juventudes en el ámbito educativo. Referencias internacionales, antecedentes y trayectoria general durante el primer franquismo», Historia de la Educación. Revista Interuniversitaria, 22-23, (Salamanca, 2003-2004), 105-121.

Charrad, Susanne; Santiago, Donald y Schouwink, Winfried, 100 Jahre/Años Deutsche Schule Barcelona/Colegio Alemán, Chronik/Crónica, Memoria 1993-1994, Barcelona, Der Vorstand des Schulvereins/Junta Directiva del Colegio, 1994.

Delgado López-Escalonilla, Lorenzo, Diplomacia franquista y politica cultural hacia Iberoamérica 1939-1953, Madrid, Consejo Superior de Investigaciones Científicas, 1988.

Delgado López-Escalonilla, Lorenzo, Imperio de papel. Acción cultural y política exterior durante el primer franquismo, Madrid, CSIC, 1992.

Delgado López-Escalonilla, Lorenzo, «Las relaciones culturales de España en tiempos de crisis: de la II República a la Guerra Mundial», Espacio, Tiempo y Forma, Serie V, 7 (Madrid, 1994), 259-294.

Düwell, Kurt, Deutschlands Auswärtige Kulturpolitik 1918-1932. Grundlinien und Dokumente, Köln/Wien, Böhlau, 1976.

Düwell, Kurt, «Die Gründung der Kulturpolitischen Abteilung im Auswärtigen Amt 1919/20 als Neuansatz. Inhaltliche und organisatorische Strukturen der Reform auswärtiger Kulturpolitik nach dem Ersten Weltkrieg», en Düwell, Kurt y Link, Werner (coords.), Deutsche Auswärtige Kulturpolitik seit 1871. Geschichte und Struktur, Köln/Wien, Böhlau Verlag, 1981; 46-71.

Düwell, Kurt, Link, Werner (coords.), Deutsche Auswärtige Kulturpolitik seit 1871. Geschichte und Struktur, Köln/Wien, Böhlau Verlag, 1981. 
Engel, Ulrich, Liebetanz, Frank, Mohr, Stephan, Pöllinger, Rike,Vidosa, Julio. 100 Jahre Deutsche Schule Madrid/ Centenario del Colegio Alemán de Madrid, Madrid, Schulverein der Deutschen Schule/ Asociación del Colegio Alemán de Madrid, 1998.

Estivill, Josep, «Comercio cinematográfico y propaganda política entre la España franquista y el Tercer Reich», Film-Historia, VII, 2 (Barcelona, 1997): 113-130. Disponible en: http://www.publicacions.ub.es/bibliotecaDigital/cinema/filmhistoria/ art.Estivill. pdf [consultado el 7 de mayo de 2013]

Gamero Merino, Carmela, «José Castillejo y la Junta: pensiones en el extranjero», en Sánchez Ron, José Manuel (coord.), 1907-1987. La Junta para ampliación de estudios e investigaciones científicas 80 años después. Simposio internacional Madrid, 15-17 de diciembre de 1987, Madrid, Consejo Superior de Investigaciones Científicas, 1988, 2; 29-46.

García Pérez, Rafael, Franquismo y Tercer Reich: las relaciones económicas hispano-alemanas durante la Segunda Guerra Mundial, Madrid, Centro de Estudios Constitucionales, 1994.

Gliech, Oliver, «Wilhelm Faupel. Generalstaboffizier, Militärberater, Präsident des Ibero-Amerikanischen Instituts», en Liehr, Reinhard; Maihold, Günther y Vollmer, Günter (coords.), Ein Institut und sein General, Wilhelm von Faupel und das Ibero-Amerikanische Institut in der Zeit des Nationalsozialismus, Frankfurt am Main, Vervuert, 2003; 131-279.

Goebbels, Joseph, Die Wahrheit über Spanien: Rede auf dem Reichsparteitag in Nürnberg, Berlin, M. Müller \& Sohn, 1937 (edición española, La verdad sobre España. Discurso pronunciado en Nuremberg en el Congreso Nacional del Partido).

Grossmann, Rudolf, «Spanien wird wieder Großmacht», Iberoamerikanische Rundschau, 6 (Hamburgo, 1941), 126-129.

Hausmann, Frank Rutger, «Auch im Krieg schweigen die Musen nicht»: Die Deutschen Wissenschaftlichen Institute im Zweiten Weltkrieg, Göttingen, Vandenhoeck \& Ruprecht, 2001. Capítulo 7. Das Deutsche Wissenschaftliche Institut in Madrid, 211-237.

Hera Martínez, Jesús de la, La política cultural de Alemania en España en el período de entreguerras, Madrid, CSIC, 2002.

Hutton, Christopher, Linguistics and the Third Reich: mother-tongue fascism, race and the science of language, London, Routledge, 1999.

Janué Miret, Marició, «Autorepresentación nacional y conflicto sociopolítico: Alemania en la Exposición Internacional de Barcelona de 1929», Spagna Contemporanea, 31 (Torino, 2007): 113-136.

Janué Miret, Marició, «La cultura como instrumento de la influencia alemana en España: la Sociedad Germano-Española de Berlín (1930-1945)», Ayer, 69 (Madrid, 2008a), 21-45.

Janué Miret, Marició, «Imperialismus durch auswärtige Kulturpolitik: die DeutschSpanische Gesellschaft als 'zwischenstaatlicher Verband' unter dem Nationalsozialismus», German Studies Review 31,1 (Austin, USA, 2008b), 109-132. 
Janué Miret, Marició, «Im Spiegel der deutschen Wissenschaft und Kultur: Stipendiaten der Junta para Ampliación de Estudios e Investigaciones Científicas (JAE) in Deutschland: La ciencia y la cultura alemanas como espejo: pensionados de la Junta de Ampliación de Estudios e Investigaciones Científicas (JAE) en Alemania», en Rebok, Sandra (coord.), Traspasar Fronteras. Un siglo de intercambio cientifico/Über Grenzen Hinaus. Ein Jahrhundert Deutsch-Spanische Wissenschaftsbeziehungen, Madrid, CSIC/DAAD, Madrid, 2010; 170-191.

Janué Miret, Marició, «Les relacions culturals mútues entre Catalunya i Alemanya en l'etapa d'auge del catalanisme fins a la fi de la Guerra Civil», en Arnabat, Ramon, Gavaldà, Antoni, (coords.), Projectes nacionals, identitats i relacions CatalunyaEspanya. Homenatge al doctor Pere Anguera (II), Catarroja/Barcelona, Editorial Afers, 2012a; 207-220.

Janué Miret, Marició, «Els treballadors «voluntaris» espanyols a Alemanya durant la Segona Guerra Mundial: la perspectiva nacionalsocialista», en Segura, Antoni, Mayayo, Andre, Abelló, Teresa, La dictadura franquista. La institucionalització d'un règim, Barcelona, Universitat de Barcelona, 2012b; 337-348.

Janué Miret, Marició, «La atracción del falangismo a la causa nacionalsocialista por parte de la Sociedad Germano-Española de Berlín durante la Guerra Civil Española», en Miguel Á. Ruiz-Carnicer, Falange. Las culturas politicas del fascismo en la España de Franco (1936-1975). Comunicaciones. Institución «Fernando el Católico» (C.S.I.C)/Excma. Diputación de Zaragoza, Zaragoza, 2013. CD-Rom; 240-261.

Janué Miret, Marició, «Woe Betide Us If They Win!: National Socialist Treatment of the Spanish 'Volunter' Workers», Contemporary European History 23/3, 2014, 329-357.

Johs, Max, «Die deutschen Schulen in Spanien 1939-1945», en Schmidt, Franz, (coord.), Deutsche Bildungsarbeit im Ausland nach dem ersten und dem zweiten Weltkriege. Erlebnisse und Erfahrungen in Selbstzeugnissen aus aller Welt, Braunschweig, Georg Westermann Verlag,1956; 206-213.

Jorba, Manuel, «Record de Hans Juretschke (1909-2004) i dels seus estudis Catalans», Anuari Verdaguer, 15 (Vic, 2007), 529-537.

Juretschke, Hans, «Das Spanienbild der deutschen Hispanistik», en Vega Cernuda, Miguel Angel (coord.), España y Europa: Estudios de crítica cultural: Obras completas de Hans Juretschke, Madrid, Editorial Complutense, 3, 2001; 1129-1136.

Laitenberger, Volkhard, «Organisations- und Strukturprobleme der Auswärtigen Kulturpolitik und des akademischen Austauschs in den zwanziger und dreissiger Jahren», en Düwell, Kurt y Link, Werner (coords.), Deutsche Auswärtige Kulturpolitik seit 1871. Geschichte und Struktur, Köln/Wien, Böhlau Verlag,1981; 72-100.

Leitz, Christian, Economic relations between Nazi Germany and Franco's Spain, 1936-1945, Oxford, Clarendon, 1996.

Leitz, Christian, «Nazi Germany and Francoist Spain, 1936-1945», en Balfour, Sebastian, Preston, Paul (coords.), Spain and the Great Powers in the Twentieth Century, London/New York, Routledge, 1999; 127-150. 
Liehr, Reinhard, Maihold, Günther, Vollmer, Günter (coords.), Ein Institut und sein General, Wilhelm von Faupel und das Ibero-Amerikanische Institut in der Zeit des Nationalsozialismus, Frankfurt am Main, Vervuert, 2003.

López García, José Antonio, «La presencia de Carl Schmitt en España», Revista de Estudios Politicos, 91 (Madrid,1996), 139-168.

López Sánchez, José María, «Política cultural exterior alemana en España durante la República de Weimar», Cuadernos de Historia Contemporánea, 25 (Madrid, 2003), 235-253.

Maier Allende, Jorge, Schattner, Thomas G., «Das Deutsche Archäologische Institut und die Archäologie der Iberischen Halbinsel/El Instituto Arqueológico Alemán y la arqueología de la península Ibérica», en Rebok, Sandra (coord.), Traspasar Fronteras. Un siglo de intercambio científico/Über Grenzen Hinaus. Ein Jahrhundert DeutschSpanische Wissenschaftsbeziehungen, Madrid, CSIC/DAAD, 2010; 330-357.

Marquina Barrio, Antonio, «La Iglesia española y los planes culturales alemanes para España», Razón y Fe, 975 (1979), 354-370.

Meseguer, Manuel Nicolás, La intervención velada: el apoyo cinematográfico alemán al bando franquista, 1936-1939, Murcia, Universidad de Murcia, 2004.

Meyenn, Karl von, «Del conocimiento científico al poder de la ciencia. Ciencia y política en Alemania durante el segundo imperio y la República de Weimar», en Sánchez Ron, José Manuel (coord.), 1907-1987. La Junta para ampliación de estudios e investigaciones científicas 80 años después. Simposio internacional Madrid, 15-17 de diciembre de 1987, Madrid: Consejo Superior de Investigaciones Científicas, 1988; 63-126.

Morant Ariño, Toni, «'Junge, tapfere Spanierinnen!' - 'Starkes und sportliches BDMMädel'. Selbst-und Fremdbilder in den Kontakten zwischen der Sección Femenina de Falange und dem Bund Deutscher Mädel in der HJ (1937-1943)», Jahrbuch für Historische Bildungsforschung 13 (Bad Heilbrunn, 2007a), 187-210.

Morant Ariño, Toni, «'Una importante expresión de amistad hispano-alemana'. Les visites de Pilar Primo de Rivera a l'Alemanya nacionalsocialista, 1938-1945», en Aldunate León, Óscar, Heredia Urzáiz, Iván (coords.), I Encuentro de Jóvenes Investigadores de Historia Contemporánea de la Asociación de Historia Contemporánea, Zaragoza, Prensas Universitarias de Zaragoza, 2007b. CD-Rom. Disponible en: http://ifc.dpz.es/recursos/publicaciones/27/15/16.tonimorant.pdf [consultado el 8 de mayo de 2013]

Morant Ariño, Toni, «'Todo ha sido como en cine'. El viatge d'un grup d'Auxilio Social a Alemanya, tardor de 1937», en Ruiz-Carnicer, Miguel Á., Falange. Las culturas políticas del fascismo en la España de Franco (1936-1975). Comunicaciones. Institución «Fernando el Católico» (C.S.I.C)/Excma. Diputación de Zaragoza, Zaragoza, 2013. CD-Rom; 317-334.

Morant Ariño, Toni, «Die Gründung des «Europäischen Jugenverbands» und die Frauen-und Jugendorganisationen der Falange (Wien, September 1942)», Themenportal europäische Geschichte Berlin, Humboldt-Universität zu Berlin. Disponible en: http://www.europa.clioonline.de/2012/Article=559 [consultado el 8 de mayo de 2013]. 
Moreno Julià, Xavier, La División Azul. Sangre española en Rusia, 1941-1945, Barcelona, Crítica, 2005.

Muñoz Aunión, Marta, «El cine español según Goebbels: Apuntes sobre la versión alemana de Carmen, la de Triana», Secuencias: revista de historia del cine, 20 (2004), 25-46.

Núñez Seixas Xosé Manoel, «¿Un nazismo colaboracionista español? Martín de Arrizubieta, Wilhelm Faupel y los últimos de Berlín (1944-45)», Historia Social, 51 (2005), 21-47

Presas Puig, Albert, «Wissenschaftliche Beziehungen zwischen Deutschland und Spanien in den zwanziger Jahren/Las relaciones científicas entre Alemania y España durante los años 20» en Rebok, Sandra (coord.), Traspasar Fronteras. Un siglo de intercambio cientifico/Über Grenzen Hinaus. Ein Jahrhundert DeutschSpanische Wissenschaftsbeziehungen. Madrid, CSIC/DAAD, 2010; 89-104.

Pöppinghaus, Ernst-Wolfgang, Moralische Eroberungen? Kultur und Politik in den deutsch-spanischen Beziehungen der Jahre 1919 bis 1933, Frankfurt a.M., Vervuert, 1999.

Rebok, Sandra, «Deutsche Wissenschaft in Spanien: Der Beginn der institutionellen Zusammenarbeit Anfang des 20. Jahrhunderts/Ciencia alemana en España: los comienzos de la cooperación institucional en los albores del siglo XX» en Rebok, Sandra (coord), Traspasar Fronteras. Un siglo de intercambio cientifico/Über Grenzen Hinaus. Ein Jahrhundert Deutsch-Spanische Wissenschaftsbeziehungen, Madrid, CSIC/DAAD, 2010; 108-137.

Rebok, Sandra, «Las primeras instituciones científicas alemanas en España: los comienzos de la cooperación institucional en los albores del siglo XX», Arbor, 187 (2011), 169-182.

Rodríguez Jiménez, José Luis, Los esclavos españoles de Hitler, Planeta, Barcelona, 2002.

Rodríguez López, Carolina, «La Universidad de Madrid como escenario de las relaciones hispano-alemanas en el primer franquismo (1939-1951)», Ayer, 69, (2008), 101-128.

Sánchez-Blanco, Francisco, «España, inspiración para conservadores alemanes; Alemania, admiración de progresistas españoles. Carl Schmitt: un ejemplo de malentendidos de fondo» en Salas, Jaime de, Briesemeister, Dietrich (coords), Las influencias de las culturas académicas alemana y española desde 1898 hasta 1936, Frankfurt a.M., Vervuert, 2000; 91-110.

Sánchez Ron, José Manuel, España y Europa, en Fontana, Josep; Villares Ramón, Historia de España, 11, Madrid, Crítica, 2008.

Sanz Díaz, Carlos, «El papel de la política cultural en las relaciones hispanoalemanas, 1949-1966», Ayer, 69, (Madrid, 2008), 155-185.

Sanz Díaz, Carlos, «Relaciones científico-culturales hispano-alemanas entre 1939 y 1975» en Rebok, Sandra (coord), Traspasar Fronteras. Un siglo de intercambio cientifico/Über Grenzen Hinaus. Ein Jahrhundert Deutsch-Spanische Wissenschaftsbeziehungen, Madrid, CSIC/DAAD, 2010; 361-380. 
Saz Campos, Ismael, España contra España. Los nacionalismos franquistas, Madrid, Marcial Pons, 2003.

Schmitt, Carl, «El concepto de Imperio en el derecho internacional», Revista de Estudios Políticos, 1 (1941), 83-101.

Sesma Landrín, Nicolás «Propaganda en la alta manera e influencia fascista. El Instituto de Estudios Políticos (1939-1943)», Ayer, 53 (2004), 155-178.

Sesma Landrín, Nicolás Antología de la 'Revista de Estudios Políticos ', Madrid, Boletín del Estado/Centro de Estudios Políticos y Constitucionales, 2009.

Sesma Landrín, Nicolás «Importando el Nuevo Orden. El Instituto de Estudios Políticos y la recepción de la cultura fascista y nacionalsocialista en España (19391942)» en Gallego, Ferran, Morente Valero, Francisco (coords.), Rebeldes y reaccionarios: intelectuales, fascismo y derecha radical en Europa, Mataró, El Viejo Topo, 2011; 243-280.

Thomàs, Joan Maria, La batalla del wolframio. Estados Unidos y España de Pearl Harbor a la Guerra Fría (1941-1947), Madrid, Cátedra, 2010.

Vega Cernuda, Miguel Ángel, «Introducción» en Vega Cernuda, Miguel Ángel, España y Europa: Estudios de crítica cultural. Obras completas de Hans Juretschke, Madrid, Editorial Complutense, 2003; IX-XXV.

Viñas Martín, Ángel, La Alemania nazi y el 18 de Julio, Madrid, Alianza Editorial, 1974.

Viñas Martín, Ángel, Guerra, Dinero, Dictadura. Ayuda fascista y autarquía en la España de Franco, Barcelona, Crítica, 1984.

Viñas Martín, Ángel, Franco, Hitler y el estallido de la Guerra Civil. Antecedentes y consecuencias, Madrid, Alianza Editorial, 2001.

Waibel, Jens, Die deutschen Auslandsschulen - Materialien zur Aussenpolitik des Dritten Reiches, Tesis doctoral, Kulturwissenschaftliche Fakultät der EuropaUniversität Viadrina, Frankfurt (Oder), 2010.

Whealey, Robert H., Hitler and Spain. The Nazi Role in the Spanish Civil War 19361939, Lexington, The University Press of Kentucky,1989.

Recibido: $10 / 05 / 2013$

Aceptado: 20/11/2013 